\title{
Cholestatic hepatocellular injury with azathioprine: A case report and review of the mechanisms of hepatotoxicity
}

\author{
Joseph Romagnuolo MD FRCPC, DC Sadowski MD FRCPC, E Lalor MB FRCPC FRACP, L Jewell MD FRCPC, \\ ABR Thomson MD PHD FRCPC FACG
}

\begin{abstract}
J Romagnuolo, DC Sadowski, E Lalor, L Jewell, ABR Thomson. Cholestatic hepatocellular injury with azathioprine: A case report and review of the mechanisms of hepatotoxicity. Can J Gastroenterol 1998;12(7):479-483. Azathioprine is a drug commonly used for the treatment of inflammatory bowel disease, organ transplantation and various autoimmune diseases. Hepatotoxicity is a rare, but important complication of this drug. The cases reported to date can be grouped into three syndromes: hypersensitivity; idiosyncratic cholestatic reaction; and presumed endothelial cell injury with resultant raised portal pressures, venoocclusive disease or peliosis hepatis. The components of azathioprine, 6-mercaptopurine and the imidazole group, may play different roles in the pathogenesis of hepatotoxicity. The strong association with male sex, and perhaps with human leukocyte antigen type, suggests a genetic predisposition of unknown type. Many of the symptoms of hepatotoxicity, such as nausea, abdominal pain and diarrhea, can be nonspecific and can be confused with a flareup of inflammatory bowel disease. As well, the subtype resulting in portal hypertension can occur without biochemical abnormalities. A 63-year-old man with Crohn's disease who is presented developed the rare idiosyncratic form of azathioprine hepatotoxicity, but also had a severe disabling steroid myopathy, peripheral neuropathy, resultant deep venous thrombosis and pulmonary embolism related to immobility, and a nosocomial pneumonia. His jaundice and liver enzyme levels improved markedly on withdrawal of the drug, returning to almost normal in five weeks. Treating inflammatory bowel disease effectively while trying to limit iatrogenic disease is a continuous struggle. Understanding the risks of treatment is the first important step. There must be a
\end{abstract}

low threshold for obtaining liver function tests, especially in men, and alertness to the need to discontinue the drug or perform a liver biopsy should patients on azathioprine develop liver biochemical abnormalities, unexplained hepatomegaly or signs of portal hypertension.

Key Words: Azathioprine, Cholestatic liver disease, Crohn's disease, Drug toxicity, Inflammatory bowel disease, Pathogenesis, Pathology

\section{Atteinte hépato-cellulaire cholestatique avec azathioprine : rapport de cas et survol des mécanismes de l'hépatotoxicité}

RÉSUMÉ : L'azathioprine est un médicament d'utilisation courante pour
le traitement de la maladie inflammatoire de l'intestin, lors de
transplantations d'organes et pour diverses maladies auto-immunes.
L'hépatotoxicité est une complication rare, mais grave, de ce médicament.
Selon nous, les cas signalés à ce jour peuvent être regroupés en trois
syndromes : hypersensibilité, réaction cholestatique idiosynchrasique et
atteinte cellulaire endothéliale présumée, avec élévation consécutive des
pressions portales, maladie veino-occlusive et péliose hépatique. La
6-mercaptopurine et le groupe imidazole, composantes de l'azathioprine,
peuvent jouer des rôles différents dans la pathogenèse. Le lien probant avec
le sexe masculin et peut-être avec le type d'HLA suggère une prédisposition
génétique. De nombreux symptômes d'hépatotoxicité, comme la nausée, la
douleur abdominale et la diarrhée peuvent être non spécifiques et se
confondre avec une exacerbation de la maladie inflammatoire de l'intestin.
De même, le sous-type entraînant l'hypertension portale peut survenir sans voir page suivante

Departments of Gastroenterology and Pathology, University of Alberta, Edmonton, Alberta

Correspondence: Dr J Romagnuolo, University of Alberta, 2G2.08 Walter C Mackenzie Health Sciences Centre, Edmonton, Alberta

T6G 2R7. Telephone 403-492-8822, fax 403-439-1922, e-mail jr5@gpu.srv.ualberta.ca

Received for publication March 18, 1998. Accepted June 10, 1998 
anomalies biochimiques. Nous présentons ici le cas d'un homme de 63 ans, atteint de maladie de Crohn, qui a développé une forme idiosynchrasique rare d'hépatotoxicité liée à l'azathioprine et qui a également souffert d'une grave myopathie thyroïdienne invalidante, de neuropathie périphérique, d'une thrombose veineuse profonde secondaire et d'embolie pulmonaire par suite de son immobilité et d'une pneumonie nosocomiale. Sa jaunisse et ses taux d'enzymes hépatiques se sont améliorés nettement à l'arrêt du médicament pour revenir presque à la normale en cinq semaines. Nous tentons toujours de traiter la maladie inflammatoire de l'intestin efficacement, en essayant de limiter toute maladie iatrogène. La première étape importante est de comprendre les risques associés au traitement. Il faut abaisser les seuils des tests de fonction hépatique, surtout chez les hommes, et ne pas hésiter à cesser le traitement ou à procéder à une biopsie hépatique si les patients sous azathioprine développent des anomalies biochimiques hépatiques, une hépatomégalie inexpliquée ou des signes d'hypertension portale.
D rug toxicity is a major limiting problem in the management of patients with inflammatory bowel disease (IBD). Azathioprine (AZA) is widely used in the treatment of Crohn's disease and other autoimmune diseases as a steroid-sparing agent, as well as in prevention of organ rejection in transplantation. While effective in reducing inflammation, the drug has many adverse effects related to bone marrow and immune suppression, pancreatitis and, rarely, hepatic injury. Judging by the paucity of reports, the frequency of hepatotoxicity with AZA appears rare, despite wide usage of the drug. It can be difficult to distinguish drug toxicity from a flare-up or complication of the primary disease because many of the diseases for which AZA is used can independently cause hepatobiliary abnormalities, and because the hepatotoxicity may cause nonspecific gastrointestinal symptoms.

We describe a patient who presented with multiple complications from medical treatment for Crohn's disease including cholestatic liver disease, severe steroid myopathy, thromboembolism from immobility and nosocomial pneumonia. We review and discuss the liver histopathology and attempt to group the pathogeneses and previously reported clinical presentations into three main syndromes.

\section{CASE PRESENTATION}

A 63-year-old male with a 14-year history of Crohn's disease presented with a five-day history of increasing jaundice, mild nausea and dark urine, without fever or pruritis. He also suffered from difficulty in walking, with leg and arm weakness progressing over several months. He also noted a $5 \mathrm{~kg}$ weight loss, fatigue and anorexia. Pancolonic involvement was previously documented and he had had a normal small bowel follow-through seven years previously. To date, he had not required surgical resection. The disease had been controlled with mesalamine until one year previously, when he developed increasing diarrhea and rectal bleeding. Oral prednisone was instituted. Attempts to taper prednisone below $20 \mathrm{mg}$ daily failed despite concomitant treatment with metronidazole $500 \mathrm{mg}$ twice daily and mesalamine $1 \mathrm{~g}$ four times daily, both continuing for almost one year. He continued to have three to four bowel movements daily with blood. Three weeks before admission he started on oral ileal-release budesonide, a steroid with high first-pass metabolism, at a dose of $9 \mathrm{mg} /$ day. In addition, he required metformin for steroid-induced glucose intolerance that was discovered six weeks before presenting. There was no significant alcohol or acetaminophen ingestion, or family history of liver disease or
IBD. Liver function tests, performed before AZA therapy began, had been normal (alanine aminotransferase $45 \mathrm{U} / \mathrm{L}$ [normal less than 40], alkaline phosphatase $66 \mathrm{U} / \mathrm{L}$ [normal less than 130], bilirubin $7 \mu \mathrm{mol} / \mathrm{L}$ [normal less than 20]). AZA $100 \mathrm{mg} /$ day (approximately $1.25 \mathrm{mg} / \mathrm{kg} /$ day) was started nine weeks before presentation. Family members had noted mild jaundice for two weeks before presentation.

On examination he was grossly icteric and afebrile with normal vital signs. He had a tender, normal-sized liver (10 cm span) with no splenomegaly, ascites or stigmata of chronic liver disease. Neurological examination showed normal tone, severe quadriceps atrophy, particularly weak neck flexion, proximal muscle weakness (especially in the lower extremities), normal reflexes and decreased vibration sensation. There was no evidence of deep venous thrombosis. He had a macular rash on his abdomen, and a palpable subcutaneous lesion on his left index finger that was suggestive of an Osler's node. Laboratory investigations revealed a hemoglobin level of $112 \mathrm{~g} / \mathrm{L}$ with a mean corpuscular volume of $95 \mathrm{fL}$, white blood cell count of $3.2 \times 10^{9} / \mathrm{L}$, aspartate aminotransferase $65 \mathrm{U} / \mathrm{L}$ (normal less than 40 ), alkaline phosphatase $896 \mathrm{U} / \mathrm{L}$ (normal less than 130), bilirubin $136 \mu \mathrm{mol} /$ $\mathrm{L}$ (normal less than 20), albumin $31 \mathrm{~g} / \mathrm{L}$, creatine kinase $7 \mathrm{U} / \mathrm{L}$, slightly low vitamin B12 level and normal lipase, renal function, thyroid function and prothrombin time. After an abdominal ultrasound suggested biliary abnormalities consistent with primary sclerosing cholangitis (PSC), an endoscopic retrograde cholangiopancreatography was performed that showed a normal biliary tree. Serologies for cytomegalovirus, Epstein-Barr virus, and hepatitis B and C were all negative as were the antismooth muscle antibody, antimitochondrial antibody and fluorescent antinuclear antibody. Immunoglobulin levels were also normal. Repeated blood cultures were negative, as was a transesophageal echocardiogram. The consulting neurologist felt that the patient's clinical findings indicated classical steroid myopathy, with mild neuropathy consistent with vitamin B12 deficiency. Nerve conduction studies showed mild peripheral neuropathy, but unfortunately electromyography failed to demonstrate myopathic changes. A muscle biopsy was considered, but deferred due to the need for anticoagulation (see below).

A percutaneous liver biopsy showed centrilobular cholestasis with focal feathery degeneration of hepatocytes and occasional ground glass hepatocytes (a reflection of enzyme induction by a drug) on light microscopy (Figure 1). The architecture and portal areas were otherwise within normal limits. There was insufficient specimen for electron micro- 


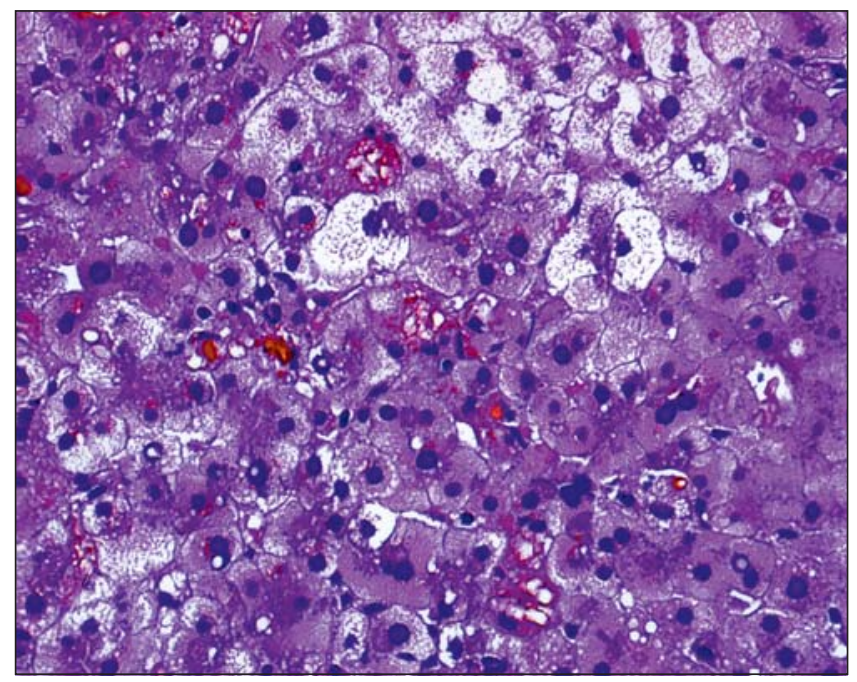

Figure 1) A high power (x40) field of the liver biopsy showing evidence of cholestasis, with examples of focal feathery degeneration and ground glass hepatocytes (hematoxylin and eosin stain)

scopy. His human leukocyte anitgen profile was A1, B8, C7, Bw6, DR17, DQ2 and DR52. Vitamin B12 was given parenterally, AZA and metronidazole were stopped, and metformin was held because of normoglycemia. Prednisone was continued at $20 \mathrm{mg} /$ day on admission, but was slowly tapered off over three weeks.

On day 6 he experienced complications due to acute respiratory distress. He was found to have a pulmonary embolism demonstrated by helical computed tomography, as well as bilateral calf deep venous thrombosis on duplex Doppler ultrasound. Because of continued dyspnea, he eventually required bronchoscopy, which recovered enterococcus. On anticoagulation, he developed epistaxis and rectal bleeding. Colonoscopy revealed near normal mucosa except for two oozing inflammatory polyps and one small colonic ulcer, all at the hepatic flexure. The bleeding stopped when the heparin was held. He was cautiously reanticoagulated because the risks were felt to be less than the benefits. However, the rectal bleeding recurred and he eventually required an inferior vena cava filter. His liver biochemistry improved significantly over his hospital stay with the alkaline phosphatase being the slowest to recover (Figure 2). His most current medications include oral budesonide $9 \mathrm{mg} / \mathrm{day}$ (to be tapered off) and mesalamine $4 \mathrm{~g} /$ day. Following five weeks in hospital, his respiratory status stabilized, his bowel symptoms were minimal and his strength was markedly improved.

\section{DISCUSSION}

Long term treatment with AZA has a reported incidence of hepatoxicity in the range of $3 \%$ to $10 \%$. The range of associated pathological entities includes hypersensitivity (1-3), cholestasis (4-6), peliosis hepatitis (7), Disse space fibrosis (8-10), veno-occlusive disease (8-12) and nodular regenerative hyperplasia (10). The latter four lesions may represent different points on a common continuum of injury.

There are also well recognized hepatobiliary complications of IBD including gallstones, PSC, pericholangitis (per-

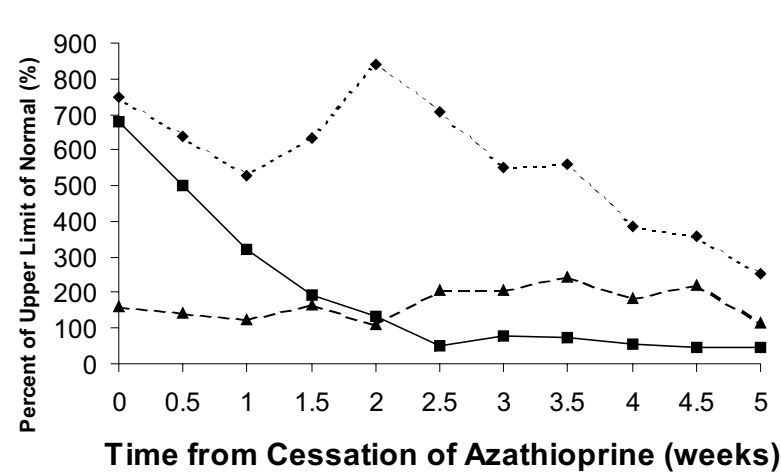

Figure 2) Graph illustrating the temporal relationship of alkaline phosphatase (dotted line), bilirubin (solid line) and aspartame aminotransferase (dashed line) to azathioprine (AZA) cessation. Upper limits of normal and baseline tests, before AZA treatment, are noted in the text

haps an early form of PSC), cholangiocarcinoma, fatty liver (with steroids, jejunoileal bypass, total parenteral nutrition and with fulminant colitis), autoimmune hepatitis and, rarely, amyloidosis or Budd-Chiari syndrome (13) (reported with ulcerative colitis) (14).

The most convincing paper linking AZA to liver damage was written by Du Vivier et al (6). Twenty-nine psoriatic patients had baseline liver biopsies and were followed with liver biopsies at six months and then annually after starting AZA. Two cases of cholestasis and eight cases of portal fibrosis were seen in follow-up. This incidence $(34 \%)$ is much higher than that recognized clinically and may be a reflection of the small sample size of the study, the possibility of other toxicities from other medications or the possibility that subclinical toxicity is much more common than is thought; however, this figure likely represents an overestimate of the frequency of complications.

In the hypersensitivity syndrome, the onset of the symptoms and signs of hepatotoxicity is usually within two to three weeks, and can rarely be associated with shock (2). Davis et al (1) attempted to explain the interesting phenomenon of a patient who experienced hepatotoxicity and hypersensitivity to AZA, but who experienced the hepatotoxicity alone, without the hypersensitivity syndrome (fever, rash, hepatitis and hypotension) when retreated with 6 mercaptopurine. AZA differs from 6-mercaptopurine only by the imidazole side chain contained in the former, which is cleaved off in vivo. It has been suggested that the 6-mercaptopurine moiety causes the idiosyncratic hepatocellular toxicity and cholestasis but that the imidazole group is responsible for the presumably immunologically mediated hypersensitivity syndrome.

A second set of changes has been seen with the predominantly cholestatic syndromes. These usually involve centrilobular necrosis and canalicular cholestasis (4). Approximately eight weeks is required for biochemical normalization after drug cessation $(2,4)$. One case of bile duct injury has been re- 
ported showing multilayered bile duct endothelium, infiltrated by neutrophils, blurred cellular limits, irregular shape, light-coloured cytoplasm, vacuolation and anisokaryosis (3). A portal infiltrate was seen with lymphocytes, histiocytes and neutrophils, mainly in the vicinity of the bile ducts. It has been suggested that this is consistent with an idiosyncratic drug reaction, as occurs with chlorpromazine, and seems to be reversible (5).

It appears that the initial injury for the third group of pathology is at the level of the endothelial cells lining the sinusoids and the terminal hepatic venules, and may occur between three months and three years of treatment (15). The location and intensity determine the type of histological changes. Extravasation of red blood cells into the Disse spaces, due to the endothelial damage, may lead to fibrosis in this area and contribute to portal hypertension. Narrowing of the lumen of the small venules, when it occurs diffusely, may be able to increase portal pressures and lead to the phenomena of portal hypertension and nodular regenerative hyperplasia (16). In the latter, obliteration of the portal venous supply of the liver causes atrophy, whether by ischemia or by lack of hepatic maintenance by hormonal factors (17) and reactive focal hyperplasia (16). The hyperplastic nodules may locally compress the sinusoids and contribute again to portal hypertension. It is also felt that endothelial damage of the sinusoids is the main initiating factor in pelio hepatis (15). Another mechanism leading to portal hypertension may be 'capillarization' of the sinusoids. Haboubi et al (15) describe Wiebel-Pallade bodies (a marker of endothelial cell proliferation), the formation of a basement membrane and the loss of fenestration in the endothelial cells. This change blocks the usual transfer of fluid from the lumen to the Disse spaces and increases sinusoidal pressure. Because this may stem from irreversible endothelial cell damage and Disse space fibrosis, withdrawal of the drug may not reverse portal hypertension, but may improve it.

Although the epidemiology of affected individuals is not well studied, the following observations can be made. Approximately $90 \%$ of patients in reported cases are male, with most of the case series containing entirely male cohorts. In

\section{REFERENCES}

1. Davis M, Eddleston AL, Williams R. Hypersensitivity and jaundice due to azathioprine. Postgrad Med J 1980;56:274-5.

2. Jeurissen MEC, Boerbooms AMT, van de Putte LBA, Kruijsen MWM. Azathioprine induced fever, chills, rash, and hepatotoxicity in rheumatoid arthritis. Ann Rheum Dis 1990;49:25-7.

3. Harvey C, Dixon JS, Bird HA. Serum IgA concentration and hepatotoxicity in rheumatoid arthritis treated with azathioprine. Br Med J 1983;287:534.

4. Horsmans Y, Rahier J Geubel AP. Reversible cholestasis with bile duct injury following azathioprine therapy. A case report. Liver 1991;11:89-93.

5. DePinho RA, Goldberg CS, Lefkowitch JH. Azathioprine and the liver. Evidence favoring idiosyncratic, mixed cholestatichepatocellular injury in humans. Gastroenterology 1984;86:162-5.

6. Du Vivier A, Munro DD, Verbov J. Treament of psoriasis with azathioprine. Br Med J 1974;i:49-51.

7. Degott C, Rueff B, Kreis H, Duboust A, Potet F, Benhamou JP. Peliosis hepatis in recipients of renal transplants. Gut 1978;19:748-53.

8. Nataf C, Feldmann G, Lebrec D, et al. Idiopathic portal addition to sex, other genetic factors may predispose certain patients to injury. In one series, three patients had very similar human leukocyte antigen types, with all three having the phenotypes A2, Bw4, Bw6, DR4 and DQw3 (not seen with our patient) (2). One report also found a low immunoglobulin A level associated with hypersensitivity syndrome. Thiopurine $S$-methyltransferase (TPMT) catalyses $S$-methylation of 6-mercaptopurine and AZA, inactivating them, and exhibits genetic polymorphism (18). Ten per cent of patients have intermediate TPMT activity, and one in 300 has TPMT deficiency. We did not determine the TPMT status of our patient. Although it is not understood what predisposes a person genetically to the adverse effect, it is likely that an immunological anomaly explains the hypersensitivity syndrome, but a defect in or alteration of the metabolism explains the simple hepatoxicity.

There are four reported cases of suspected metronidazole (another nitromidazole derivative) hepatotoxicity, one in renal failure (19) and another in overdose (20). Three 5 aminosalycilic acid associated reports exist, two of which are available for review $(21,22)$. Our patient had been taking a standard metronidazole dose with normal renal function, and the mesalamine was continued throughout his hospitalization, while liver enzymes improved. Our review of the literature did not identify any convincing reports involving metformin. The clinical, biochemical and pathological features together strongly suggest that our patient had an idiosyncratic cholestatic reaction to AZA.

In conclusion, recognizing liver involvement as a rare complication of AZA therapy is important, especially in male patients. There should be a low threshold for obtaining liver function tests, especially when faced with nonspecific symptoms atypical for a flare-up of IBD. Present et al (23) and Sandborn (24) believe that it is not unreasonable to obtain liver enzymes every three to four months for the first year and every four to six months thereafter. Some of the reported complications, including portal hypertension, may occur without biochemical abnormalities; therefore, liver biopsy should be considered when any signs of portal hypertension or unexplained hepatomegaly are present.

hypertension (perisinusoidal fibrosis) after renal transplantation. Gut 1979;20:531-7.

9. Liano F, Moreno A, Matesanz R, et al. Veno-occlusive hepatic disease of the liver in renal transplantation: is azathioprine the cause? Nephron 1989;51:509-16.

10. Mion F, Napoleon B, Berger F, Chevallier M, Bonvoisin S, Descos L. Azathioprine induced liver disease nodular regenerative hyperplasia of the liver and perivenous fibrosis in a patient treated for multiple sclerosis. Gut 1991;32:715-7.

11. Katzka DA, Saul SH, Jorkasky D, Sigal H, Reynolds JC, Soloway RD Azathioprine and hepatic venoocclusive disease in renal transplant patients. Gastroenterology 1986;90:446-54.

12. Lemley DE, Delacy LM, Seeff LB, Ishak KG, Nashel DJ. Azathioprine induced hepatic veno-occlusive disease in rheumatoid arthritis. Ann Rheum Dis 1989;48:342-6.

13. Chesner IM, Muller S, Newman J. Ulcerative colitis complicated by Budd-Chiari syndrome. Gut 1986;27:1096-100.

14. Sherlock S, Dooley J. The Diseases of the Liver and Biliary System. 10th edn. Oxford: Blackwell Scientific Publications, 1997.

15. Haboubi NY, Ali HH, Whitwell HL, Ackrill P. Role of endothelial 
cell injury in the spectrum of azathioprine induced liver disease after renal transplant: light microscopy and ultra structural observations. Am J Gastroenterol 1988;83:256-61.

16. Wanless IR, Godwin TA, Allen F, Feder A. Nodular regenerative hyperplasia of the liver in hematologic disorders: a possible response to obliterative portal venopathy. A morphometric study of nine cases with an hypothesis on the pathogenesis. Medicine 1980;59:367-79.

17. Starzl TE, Watanabe K, Porter KA, Putnam CW. Effects of insulin, glucagon, and insulin/glucagon infusions on liver morphology and cell division after complete portacaval shunt in dogs. Lancet 1976;i:821-5.

18. Yates CR, Krynetski EY, Loennechen T, et al. Molecular diagnosis of thiopurine S-methyl transferase deficiency: genetic basis for azathioprine and mercaptopurine intolerance. Ann Intern Med 1997;126:608-14.

19. Hestin D, Hanesse B, Frimat L, Trechot P, Netter P, Kessler M.
Metronidazole-associated hepatotoxicity in a hemodialyzed patient. Nephron 1994;68:286. (Lett)

20. Lam S, Bank S. Hepatoxicity caused by metronidazole overdose. Ann Intern Med 1995;122:803. (Lett)

21. Burke DA, Manning AP, Williamson JM, Axon AT. Adverse reactions to sulphasalazine and 5-amino salicylic acid in the same patient. Aliment Pharmacol Ther 1987;1:201-8.

22. Mulder H, Gratama S. Azodisalicylate (Dipentum)-induced hepatitis? J Clin Gastroenterol 1989;11:708-11.

23. Present DH, Meltzer SJ, Krumholz MP, Wolke A, Korelitz BI. 6-Mercaptopurine in the management of inflammatory bowel disease: Short- and long-term toxicity. Ann Intern Med 1989;111:641-9.

24. Sandborn WJ. A review of immune modifier therapy for inflammatory bowel disease: azathiopirine, 6-mercaptopurine, cyclosporine, and methotrexate. Am J Gastroenterol 1996;91:423-33. 


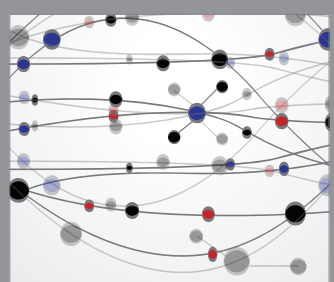

The Scientific World Journal
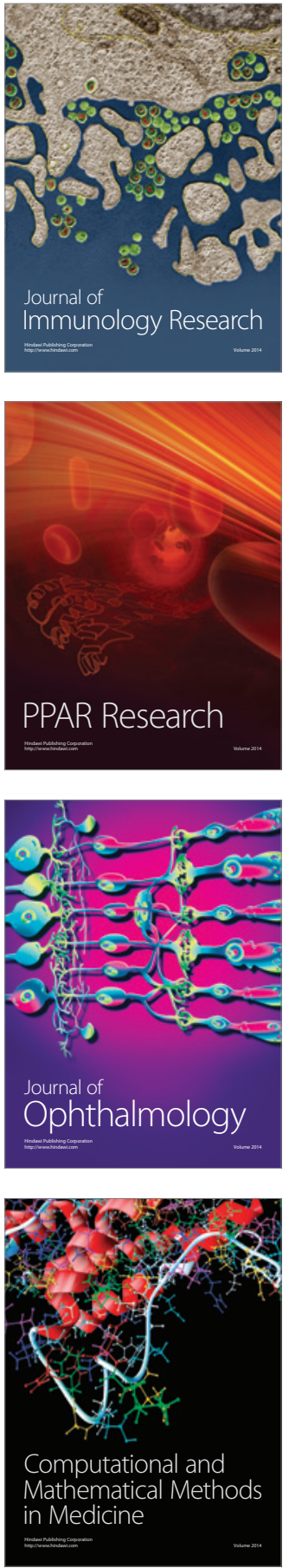

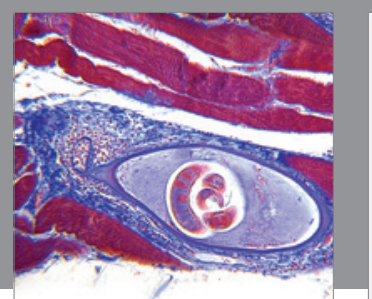

Gastroenterology Research and Practice

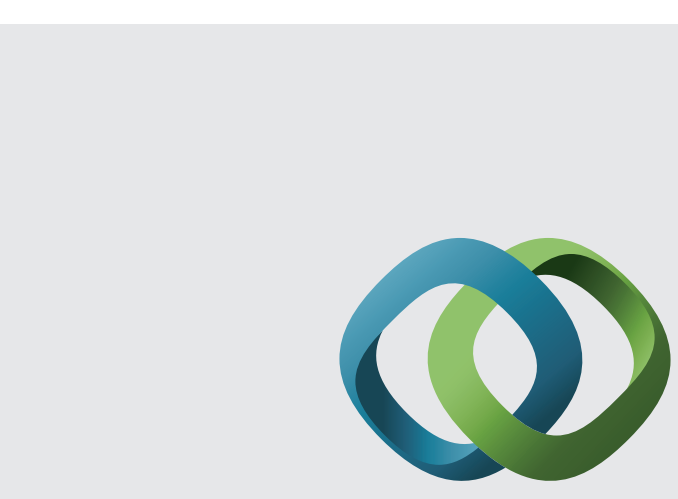

\section{Hindawi}

Submit your manuscripts at

http://www.hindawi.com
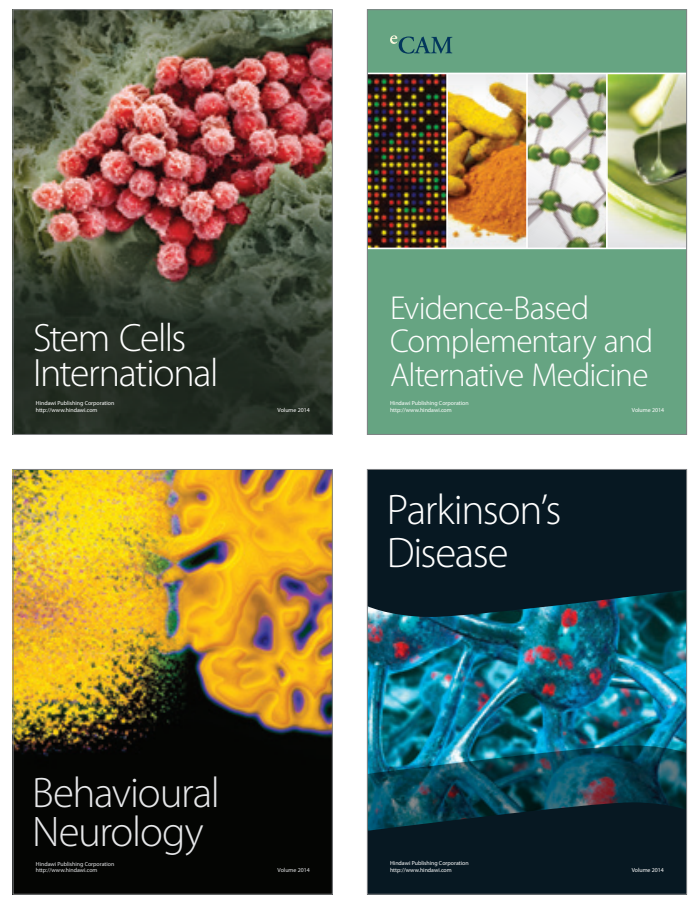
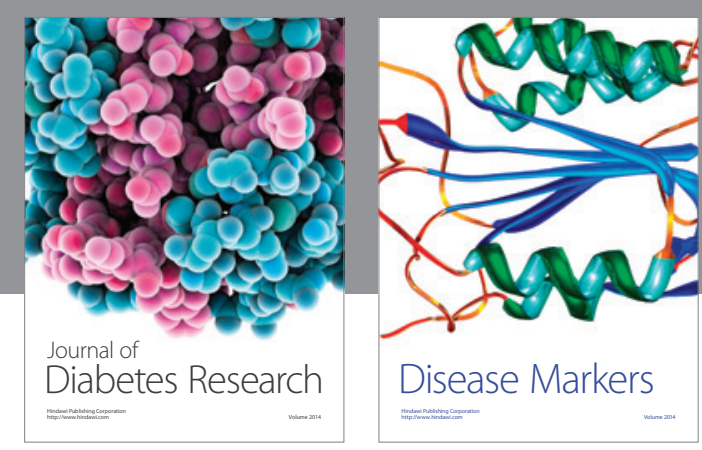

Disease Markers
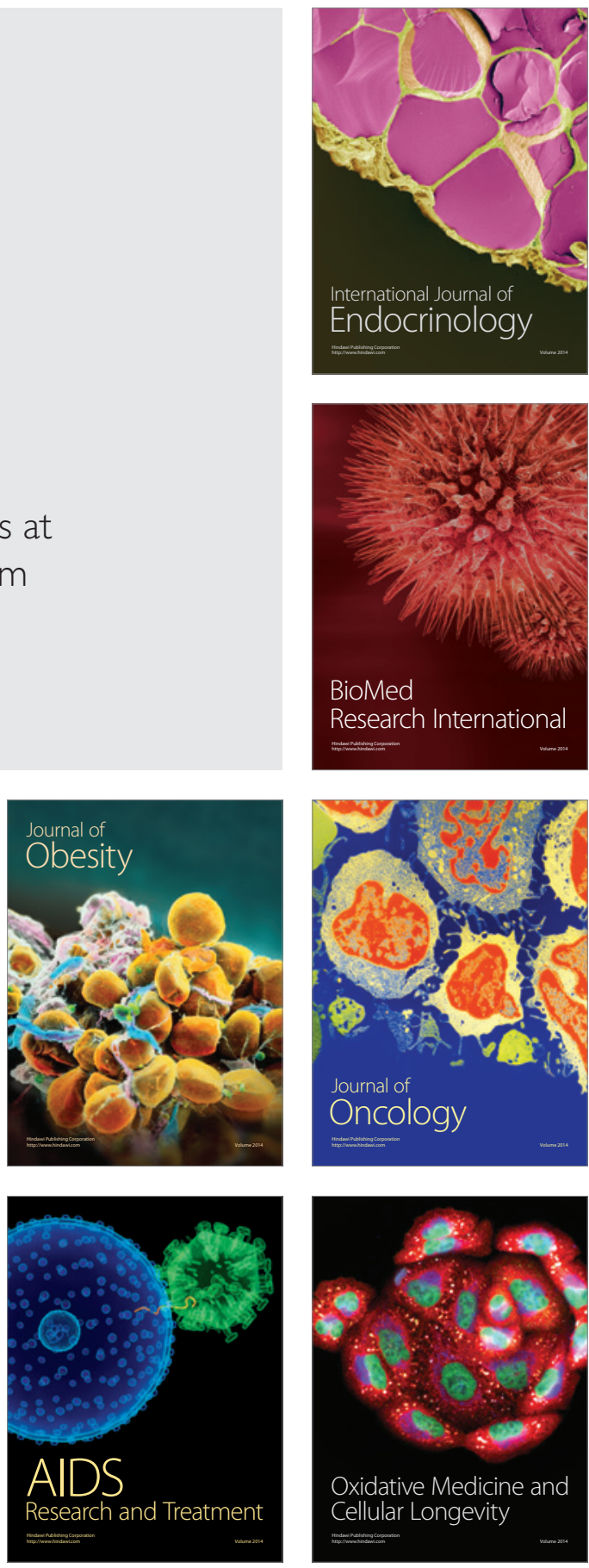